Article available at nttp://Www.parasite-journal.org or nttp://dx.dol.org/10.1051/parasite/1994013227

\title{
Plasmodium yoelII NIGERIENSIS : BIOLOGICAL MECHANISMS OF RESISTANCE TO CHLOROQUINE
}

\author{
BEAUTÉ-LAFITTE A*., ALTEMAYER-CAILLARD V.*, CHABAUD A.G.* and LANDAU I.*
}

\section{Summary :}

The sensitivity to chloroquine according to the degree of synchronicity of Plasmodium yoelii nigeriensis, which is considered to be the most resistant of the rodent malaria strains, was studied. The infection was synchronised by means of a Percoll-glucose gradient which separates rings and young trophozoites from other stages. The mid term trophozoite, when it predominated in the blood at the time of treatment, was shown to be as sensitive to chloroquine as Plasmodium vinckei petteri. According to previous results indicating that part of the population of merozoites is latent and penetrates around midnight, the inoculations were timed in order to obtain a lower or higher degree of synchronisation. The infection appeared to be better synchronised if rings and young trophozoites, were inoculated at 06:00 hrs rather than at 15:00 hrs and consequently the efficacy of chloroquine was higher in the former than in the latter.

KEY WORDS : Plasmodium yoelii nigeriensis. Sporozoa. Rodent malaria. chloroquine. chemoresistance. merozoite latency. asynchronism. ABBREVIATIONS : Ring (R); Young-trophozoite (YT): Mid-trophozoite (MT): Old-trophozoite (OT); Schizont (S); Intraperitoneal (IP); Intravenous (IV): Subcutaneous (SC); Multiplication rate (MR); Standard deviation (SD): Resistance index (RI); Synchronicity index (SI): Chloroquine (CQ).

\section{INTRODUCTION}

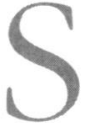

everal murine malaria Plasmodium species show a spontaneous stable cross-resistance to various antimalarial treatments. Plasmodium yoelii yoelii 17X (Warhurst and Killick-Kendrick, 1967; Diggens and Gregory, 1969), P. berghei NK65 (Diggens et al., 1969) and P. yoelii nigeriensis (Diggens et al., 1969; Pande and Dutta, 1982) infections are to various extents innately resistant to chloroquine, quinine, mepacrine, amodiaquine and mefloquine. Beauté-Lafitte et al. (in press) showed with a prepatency test, that the minimum effective single dose of chloroquine active on $P . y$. nigeriensis was $50 \mathrm{mg} / \mathrm{kg}$, i.e, 20 fold higher than that active against P. vinckei petteri $(2.5 \mathrm{mg} / \mathrm{kg})$. Interestingly, the biology of P. y. nigeriensis is also different: whe-

\footnotetext{
* Laboratoire de Biologie Parasitaire associé au C.N.R.S., (URA 114) et Laboratoire de Protozoologie et Parasitologie comparée (EPHE), Museum National d'Histoire Naturelle, 61 rue Buffon, 75231 Paris cédex 05 , France.

Correspondence: Landau I. Tel: 33-1-40793500 Fax: 33-1-40793499
}

Résumé : MÉCANISMES DE LA RÉSISTANCE À LA CHLOROQUINE CHEZ PLASMODIUM YOELII NIGERIENSIS

Le rapport entre asynchronicité et chimiorésistance est analysé chez Plasmodium yoelii nigeriensis qui, parmi les sous-espèces connues de Plasmodiums de Rongeurs, est celle qui est spontanément la plus résistante à la chloroquine.

L'infection est synchronisée au moyen d'un gradient de Percoll Glucose qui sépare les anneaux et les jeunes trophozoïtes des autres stades. Lorsque, avec ces infections rendues synchrones, le stade trophozoïte moyen est prédominant au moment du traitement, la chimiorésistance du Plasmodium disparait.

Des travaux précédents ont montré qu'une partie des mérozoïtes libérés à la fin de la schizogonie reste latente et pénètre préférentiellement dans les hématies aux environs de minuit. Les stades jeunes synchronisés par le Percoll-glucose ont donc été inoculés à deux moments différents: soit à 6 heures pour que, à minuit, la schizogonie coïncide avec l'heure de pénétration préférentielle des mérozoiltes latents, soit à 15 heures moment où cette coïncidence n'existe plus. Il est constaté que dans le premier cas, l'infection est plus synchrone et plus sensible au traitement que dans le second cas.

MOTS CLES : Plasmodium yoelii nigeriensis. sporozoa. Plasmodiums de rongeurs. chloroquine chimiorésistance latence des mérozoiltes. asynchronisme.

reas $P . v$. petteri infection is markedly synchronous with a schizogonic cycle of 24 hours, the parasitic development of P. y. nigeriensis in the blood of mice is naturally highly asynchronous, with a prolonged latency of a part of the population of merozoites which penetrate preferentially around midnight (Landau and Chabaud, 1980; Beauté-Lafitte et al., 1993) and a short schizogonic cycle of 18 hours (Deharo et al., 1994). A classification of 10 species, subspecies and strains of rodent Plasmodia according to their degree of sensitivity to chloroquine on one hand, and the extent of asynchronicity on the other hand, evidenced a correlation between asynchronicity and drug resistance (Beauté-Lafitte et al., in press).

To confirm the role of asynchronicity in the drug resistance, it appeared necessary to study the doseresponse effect of chloroquine in ordinary laboratory conditions, the potency of chloroquine on the sensitive stage of $P . y$. nigeriensis, the mid term trophozoite (MT) and finally, the variations of resistance according to the degree of synchronicity achieved by its artificial synchronization in the laboratory. 


\section{MATERIALS AND METHODS}

MICE

Outbred male Swiss mice (Charles-River, France) weighing 18-20 grams were used.

\section{STRAINS}

Expriments were performed with $P . y$. nigeriensis (NIG strain) from Nigeria. Published results (Cambie et al., 1991) on P. v. petteri (279 BY strain) from the Central African Republic were used for comparisons with P. y. nigeriensis.

\section{Mice INFECTIONS}

Asynchronous infections: Mice were inoculated intraperitoneally (IP) with $0.2 \mathrm{ml}$ of thawed blood from the same stock of aliquoted frozen infected blood. The stock comprised pooled blood taken from 10 mice with a parasitemia of 20 to $30 \%$ and frozen at $-70^{\circ} \mathrm{C}$ with added glycerol, $5 \%$ final concentration. Since the onset of visible infection (parasitemias of 0.5 to $1 \%$ ) parasite development was asynchronous.

Synchronized cycle : Synchronised infections were obtained by the method described by Deharo et al. (1994). Briefly, infected pooled blood from mice with parasitemias ranging from 15 to $25 \%$, was centrifuged through a Percoll-glucose gradient which separates rings and young trophozoites from all other stages. Mice were inoculated intravenously (IV) with $0.5 \mathrm{ml}$ of a suspension of RBC, 30\% of which were infected by these young stages. With this procedure, the immediate resulting parasitemia in the receptor mice was 0.5 to $2 \%$; the infection remained reasonably synchronous for the first two schizogonic cycles. The first schizogony occurred 15 hours post-inoculation and the following one 18 hours later.

\section{SENSITIVITY TESTS}

Non-synchronized infections : Mice were inoculated with frozen-thawed blood and were treated with a subcutaneous (SC) injection of a single dose of chloroquine base as soon as parasites were detected in the blood.

Synchronized infections : In man, peak plasma concentration of $\mathrm{CQ}$ is reached in less than 30 minutes after injection (White et al., 1987). Shorter times (15'-20') were observed in mice (Cambie et al., unpublished). Thus, treatment was administered SC on the patent infection at the time when MTs predominated, i.e., 9 hrs after the inoculation of Rs and YTs (from the Percoll-glucose gradient) or 12 hrs after the first schizogony.
FOLLOW UP OF PARASITEMIAS AND PARASITIC PATTERNS

Blood smears were prepared just prior to drug injection, $3 \mathrm{hrs}$ and $12 \mathrm{hrs}$ post-treatment, fixed in methanol and stained with Giemsa stain. Parasitemia was determined by counting at least 1500 cells, differentiating the various stages of parasite development to determine the parasitic pattern. The parasitic pattern is the percentage of each of the following parasite stages: R, YT, MT, OT, S, defined by Cambie et al. (1991) and Caillard et al. (1992). A synchronicity index (SI) was calculated as follows: SI $=$ SD of the percentage of each stage / 50 (50 being the SD in a $100 \%$ synchronous infection). The index varies from 0 (asynchronicity) to 1 (synchronicity).

\section{RESULTS}

SPONTANEOUS RESISTANCE OF $P . Y$. NIGERIENSIS TO CHLOROQUINE

T wo single doses of chloroquine were given to two batches of mice inoculated with frozenthawed blood, 66 hours post-inoculation, when parasitemias were approximately $1 \%$. One batch of 8 and one of 7 mice were treated, respectively, with 5 and $50 \mathrm{mg} / \mathrm{kg}$. A third batch of 5 untreated mice was kept as control. Blood smears were performed at the time of treatment, 3 hrs post treatment and $12 \mathrm{hrs}$ post treatment.

Just prior to drug injection, the infection was asynchronous, the parasitic pattern (not shown) displayed the presence of all stages. Three hours post-treatment, the parasitemia of control and treated mice increased slightly (Table I). Twelve hours post-treatment, the average rate of multiplication in control mice was $3.2 \pm 0.26$, and slightly less in mice treated with $5 \mathrm{mg} / \mathrm{kg}(2.2 \pm 0.4)$ and $50 \mathrm{mg} / \mathrm{kg}(1.8 \pm 0.57)$. The multiplication rate was not significantly different between treated mice $5 \mathrm{mg} / \mathrm{kg}$ and treated mice 50 $\mathrm{mg} / \mathrm{kg}$ (Test $\mathrm{U}, \mathrm{P} \leq 0.05$ ). The efficacy of the treatment was very low and independent of the dose.

\section{SENSITIVITY OF MTS TO CHLOROQUiNE}

In order to study the sensitivity of MTs the strain was first synchronized with a Percoll-glucose gradient. Mice were inoculated at 13:00 with the gradient layer containing mostly Rs. A single dose of $5 \mathrm{mg} / \mathrm{kg}$ chloroquine was injected SC 9 hrs post-inoculation, at 22:00, when Rs had developed into MTs. This procedure was repeated twice (experiments 1 and 2). Blood smears were prepared just prior to treatment, 3 


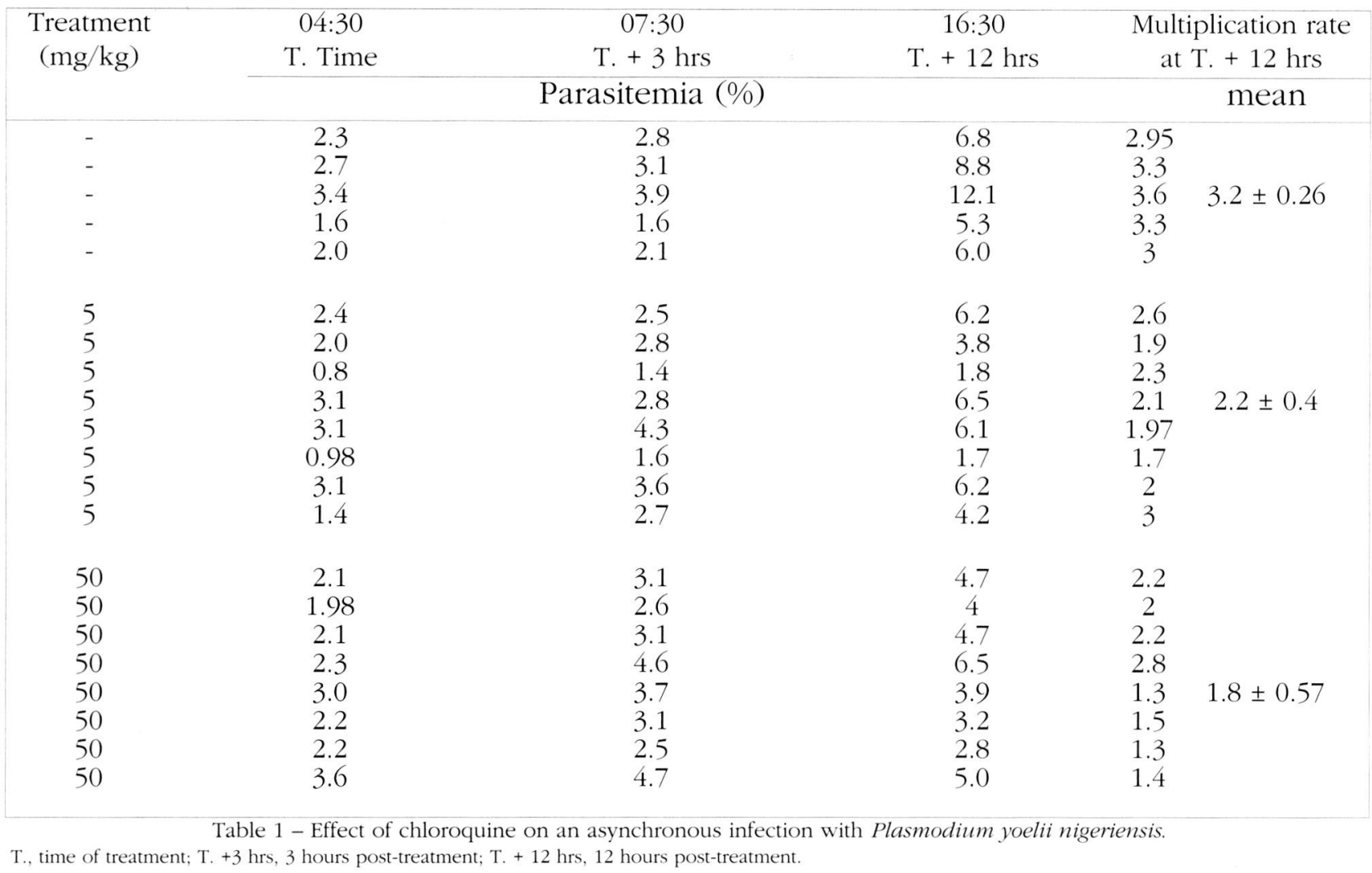

hrs post-treatment when the transformation of MTs into OTs was observed, and 12 hrs post-treatment (6 hrs after the first schizogony), and the parasitic pattern and parasitemia were analysed. Control mice were observed in parallel.

Results are depicted in Table II. In all mice, infection developed synchronously. In the control mice, parasite stages developed as expected with $P$. y. nigeriensis : MTs developed into OTs within three hours; YTs peak occured at 10:00, six hours after the time of the predicted schizogony; the multiplication rate between 22:00 and 10:00 the next day was 2.6 (experiment 1) and 3.2 (experiment 2). In the treated mice, the transformation of MTs into OTs 3 hours post-treatment was diminished in comparison with that in the control mice, and the remaining MTs showed signs of degeneration: drug-induced vacuolisation of the cytoplasm and the characteristic pigment clumping. Twelve hours post-treatment the parasitemia stagnated, showing that schizogony did not occur. The YT stage expected at 10:00, i.e., 6 hrs post-schizogony, was almost completely obliterated and the predominant stage seen was altered OTs.

The activity of chloroquine $(5 \mathrm{mg} / \mathrm{kg}$ ) on the MT stage of P.y.nigeriensis appears to be comparable to that of the same dose on the MTs of $P . v$. petteri. Cambie et al. (1991) showed with P. v. petteri the same morphological alterations, as well as an impairement of the transformation of MTs into OTs, resulting in an almost complete loss of schizogony and a decrease of parasitemia. However, due to the differences in the biology of the two species, the results are not exactly the same. The developmental cycle of P. v. petteri is 24 hours instead of 18 hours in P. $y$. nigeriensis and the transformation of MTs into OTs takes 6 hours instead of 3 hours respectively. In consequence, i) due to its rapid pharmacokinetics, the effect of chloroquine 3 hours or 6 hours postinjection is not absolutely equivalent ; ii) damaged MTs may take more than 3 hours to be eliminated from the circulation and thus, be computed or not, according to the species, when evaluating the parasitemia and the parasitic pattern. In conclusion, despite these delineated differences, it appears that the MTs of $P . y$. nigeriensis and those of $P . v$. petteri are equally sensitive to chloroquine.

\section{SEnSITIVITY OF P.Y. NIGERIENSIS ACCORDING TO THE SYNCHRONICITY OF THE INFECTION}

We have previously studied the development of the parasitemia of $P$. $y$. nigeriensis during the first schizogonic cycles following the synchronization by the Percoll-glucose gradient (Beauté-Lafitte et al., 1993). 


\begin{tabular}{cccc}
\multicolumn{5}{c}{ EXPERIMENT 1 } \\
Time & T. & T. +3 hrs & T. +12 hrs \\
22:00 & $01: 00$ & $10: 00$ \\
Par. \% & 1.4 & 1.3 & 1.7 \\
R & 3 & 3 & 7 \\
YT & 31 & 5 & 34 \\
MT & $\underline{106}$ & $60^{*}$ & 24 \\
OT & 0 & $\underline{62}$ & $58^{*}$ \\
S & 0 & 0 & 43 \\
Par. \% & 2 & 1.4 & 1.2 \\
R & 2 & 3 & 5 \\
YT & 20 & 6 & 30 \\
MT & $\underline{172}$ & $90^{*}$ & 19 \\
OT & 6 & $\underline{42}$ & $32^{*}$ \\
S & 0 & 0 & 34 \\
Par. \% & Control mouse & \\
R & 1.6 & 1.9 & 4.1 \\
YT & 22 & 2 & 49 \\
MT & 34 & 2 & $\underline{238}$ \\
OT & $\underline{104}$ & 99 & 16 \\
S & 0 & $\underline{86}$ & 21 \\
& 0 & 2 & 86 \\
\hline
\end{tabular}

\begin{tabular}{|c|c|c|c|}
\hline \multicolumn{4}{|c|}{ EXPERIMENT 2} \\
\hline Time & $\begin{array}{c}\mathrm{T} . \\
\text { 22:00 }\end{array}$ & $\begin{array}{c}\text { T. }+3 \text { hrs } \\
01: 00\end{array}$ & $\begin{array}{c}\text { T. }+12 \mathrm{hrs} \\
10: 00\end{array}$ \\
\hline \multicolumn{4}{|c|}{ Treated mice } \\
\hline Par. \% & 0.5 & 0.6 & 0.5 \\
\hline $\mathrm{R}$ & 3 & 0 & 6 \\
\hline YT & 2 & 0 & $\underline{12}$ \\
\hline MT & 39 & $38^{*}$ & $\overline{3}$ \\
\hline OT & 7 & $\underline{22}$ & $18^{*}$ \\
\hline $\mathrm{S}$ & 0 & 0 & 13 \\
\hline Par. \% & 0.6 & 0.6 & 0.6 \\
\hline $\mathrm{R}$ & 2 & 0 & 4 \\
\hline YT & 2 & 2 & $\underline{11}$ \\
\hline MT & 51 & $28^{*}$ & $\overline{2}$ \\
\hline OT & 5 & 31 & $19^{*}$ \\
\hline S & 0 & 0 & 25 \\
\hline \multicolumn{4}{|c|}{ Control mouse } \\
\hline Par. $\%$ & 0.5 & 0.7 & 1.6 \\
\hline $\mathrm{R}$ & 6 & 4 & 14 \\
\hline YT & 4 & 4 & $\underline{118}$ \\
\hline MT & 32 & 15 & $\overline{11}$ \\
\hline OT & 2 & $\underline{48}$ & 2 \\
\hline $\mathrm{S}$ & 0 & 2 & 14 \\
\hline
\end{tabular}

Table II - Evolution of the parasitic pattern and the parasitemia of Plasmodium yoelii nigeriensis after the injection of a single dose of chloroquine $5 \mathrm{mg} / \mathrm{kg}$ at the time of mid-term trophozoites predominance.

* Altered parasites, T. time of treatment.

Underlined stages : the progression of parasite propagation can be followed by reading the parasitic stages in third row column 1 to column 2 in the fourth row and again in column 3 of the second row.

We showed that the parasitemia varied according to the time of inoculation and suggested that this phenomenon was related to the rate of penetration of latent merozoites which was mostly around midnight. Thus, when the time of inoculation was set so that the time of the first schizogony coincided with the optimal time of penetration of latent merozoites, i. e., around midnight, intraerythrocytic parasitemias increased greatly over a short period, thus reinforcing the synchronicity of the parasite. The protocol for our experiment is summarized in Fig.1. The inoculum comprised of Rs obtained through a Percoll-glucose gradient and diluted to $1 / 4$ in saline. It was inoculated IV to batches of mice either at 06:00 or at 15:00, the first promoting a better synchronization than the second: the inoculation performed at 06:00 favours the synchronicity, the time of the first schizogony (21:00) allowing the simultaneous penetration of latent and rapid merozoites. To the contrary, when the inoculation is performed at 15:00, the time of the first schizogony (06:00) is well away from the preferential time of penetration of latent merozoites. The experiments were performed three times with two batches of mice: one of control untreated mice and one treated SC with $50 \mathrm{mg} / \mathrm{kg}$ chloroquine. To evaluate the differences of degree of synchronicity between inoculations at $15: 00$ and at 06:00, we calculated, for each mouse, at the time of treatment, the synchronicity index (SI). To evaluate the treatment's efficacy we calculated the multiplication rate (MR) of each treated and control mice between the time of treatment and $12 \mathrm{hrs}$ post treatment and the resistance index $(\mathrm{RI}=\mathrm{MR}$ in treated groups $/$ mean MR in control groups).

Results of the three experiments are gathered in Table III and correlation between RI and SI is in Figure 2.

Inoculations performed at 06:00 result in a more synchronous infection than that obtained with inoculation at 15:00, as judged by the SI values (Test U, P $\leq$ $0.05)$. The relationship between the degree of chloroquine's efficacy and that of the parasites' synchronicity is shown (Figure 2): the more asynchronous the parasite (low SI) the more resistant (high RI) $(\mathrm{P}<0.01$ by Spearman's rank test). 


\section{IV inoculation}

口

06:00

1

$\mathrm{R}$
Treatment CQ $50 \mathrm{mg} / \mathrm{kg}$ Blood smear just before treatment

\section{Blood smear}

12 hrs post-treat.

21:00

48 hours

09:00

21:00

Schizogony 1
09:00

MT

Schizogony 2

Treatment CQ $50 \mathrm{mg} / \mathrm{kg}$ Blood smear just before treatment

IV inoculation

!

15:00

1

$\mathrm{R}$

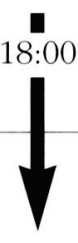

MT

\section{Schizogony 1}

00:01
Blood smear

12 hrs post-treat.

06:00

48 hours

Figure 1. - Schematic protocol for studying the efficacy of chloroquine according to the degree of synchronisation i.e. the time of inoculation.

IV : intraveinous; treat. : treatment.

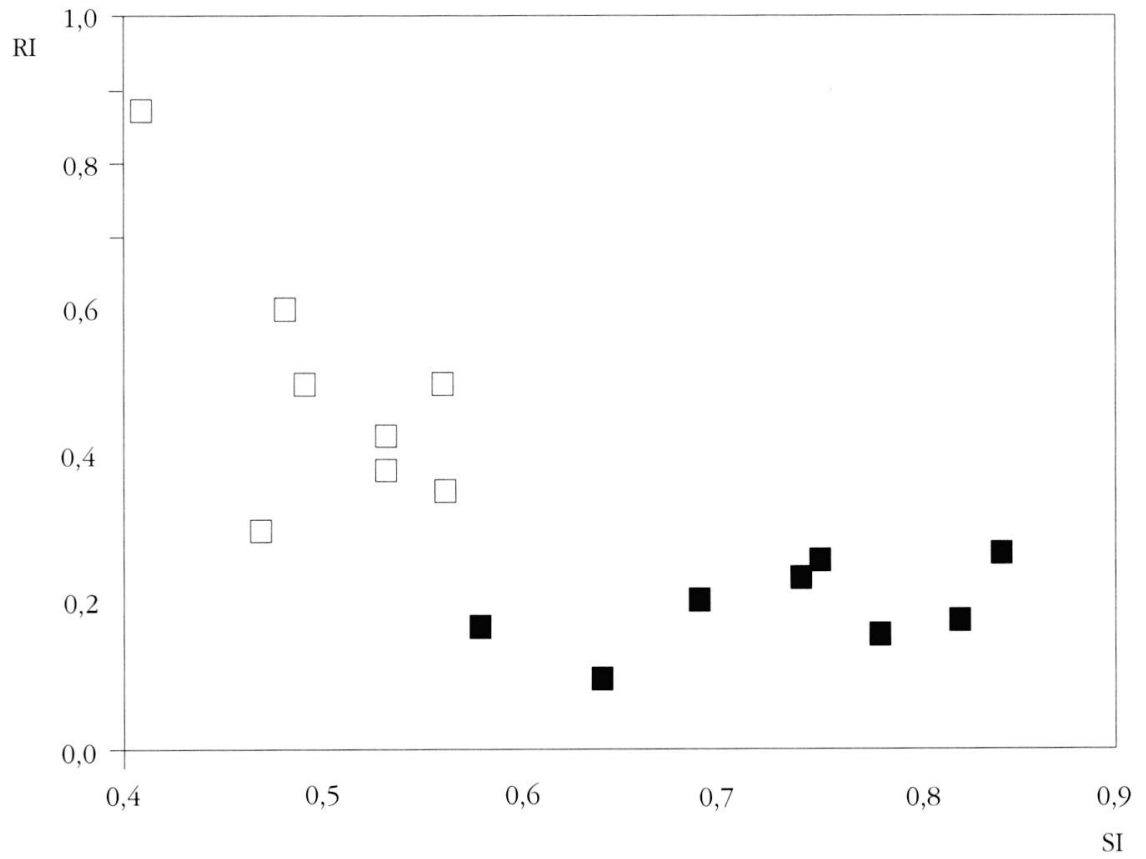

Figure 2. -Relationship between the degree of synchronicity (SI) and the sensitivity to $50 \mathrm{mg} / \mathrm{kg}$ chloroquine (RI) of Plasmodium yoelii nigeriensis.

SI : synchronicity index; RI : resistance index.

anoculation at 06:00; $\mathbf{D}$ inoculation at $15: 00$. 


\begin{tabular}{|c|c|c|c|c|c|c|c|c|c|}
\hline \multicolumn{5}{|c|}{ CONTROL MICE - INOCULATION 15:00 } & \multicolumn{5}{|c|}{ CONTROL MICE - INOCULATION 06:00 } \\
\hline \multicolumn{2}{|c|}{ Parasitemia (\%) } & \multirow{2}{*}{$\begin{array}{c}\text { MR } \\
\text { mean }\end{array}$} & \multicolumn{2}{|c|}{ SI } & \multicolumn{2}{|c|}{ Parasitemia (\%) } & \multirow{2}{*}{$\begin{array}{c}\text { MR } \\
\text { mean }\end{array}$} & \multicolumn{2}{|c|}{ SI } \\
\hline $\mathrm{T}$. & T. +12 hrs & & & mean & $\mathrm{T}$. & $\mathrm{T} .+12 \mathrm{hrs}$ & & & mean \\
\hline 2.5 & 12 & & 0.55 & & 0.9 & 3.4 & & 0.78 & \\
\hline 1.8 & 7.5 & & 0.61 & & 0.2 & 0.6 & & 0.65 & \\
\hline 2.8 & 15.3 & & 0.54 & & 4.8 & 13.2 & & 0.69 & \\
\hline 2.4 & 5.3 & $4 \pm 1.08$ & 0.52 & $0.54 \pm 0.04$ & 1.95 & 9.1 & $3.5 \pm 0.6$ & 0.59 & $0.68 \pm 0.08$ \\
\hline 6.9 & 31 & & 0.5 & & 0.3 & 0.9 & & 0.54 & \\
\hline 5.3 & 19 & & 0.5 & & 7.9 & 28.5 & & 0.73 & \\
\hline 3.3 & 11 & & 0.53 & & 8.2 & 24.6 & & 0.80 & \\
\hline- & - & - & - & - & 2 & 7.5 & & 0.68 & \\
\hline
\end{tabular}

\begin{tabular}{|c|c|c|c|c|c|c|c|c|c|c|c|}
\hline \multicolumn{6}{|c|}{ TREATED MICE - INOCULATION 15:00 } & \multicolumn{6}{|c|}{ TREATED MICE - INOCULATION 06:00 } \\
\hline \multicolumn{2}{|c|}{ Parasitemia (\%) } & \multirow[t]{2}{*}{ MR } & \multicolumn{2}{|c|}{ SI } & \multirow[t]{2}{*}{ RI } & \multicolumn{2}{|c|}{ Parasitemia (\%) } & \multirow[t]{2}{*}{ MR } & \multicolumn{2}{|c|}{ SI } & \multirow[t]{2}{*}{ RI } \\
\hline $\mathrm{T}$. & T.+12 hrs & & & mean & & $\mathrm{T}$. & T. +12 hrs & & & mean & \\
\hline 5.3 & 18.6 & 3.5 & 0.41 & & 0.87 & 2.3 & 1.9 & 0.83 & 0.74 & & 0.24 \\
\hline 8.2 & 19.7 & 2.4 & 0.48 & & 0.6 & 3 & 1.9 & 0.6 & 0.58 & & 0.17 \\
\hline 5.4 & 6.3 & 1.2 & 0.47 & & 0.3 & 3.9 & 1.4 & 0.36 & 0.64 & & 0.1 \\
\hline 2.1 & 2.9 & 1.4 & 0.56 & $0.5 \pm 0.05$ & 0.35 & 8.5 & 5.4 & 0.64 & 0.82 & $0.73 \pm 0.08$ & 0.18 \\
\hline 5.2 & 9 & 1.7 & 0.53 & & 0.43 & 7.7 & 5.6 & 0.73 & 0.69 & & 0.21 \\
\hline 5.9 & 11.7 & 1.98 & 0.56 & & 0.5 & 7.2 & 6.9 & 0.96 & 0.84 & & 0.27 \\
\hline 7.4 & 11.1 & 1.5 & 0.53 & & 0.38 & 8.4 & 4.8 & 0.57 & 0.78 & & 0.16 \\
\hline 5 & 10.2 & 2 & 0.49 & & 0.5 & 7 & 6.3 & 0.9 & 0.75 & & 0.26 \\
\hline
\end{tabular}

Table III - Activity of chloroquine according to the higher (inoculation at 06:00) or lower (inoculation at 15:00) degree of synchronisation of Plasmodium yoelii nigeriensis by means of a percoll-glucose gradient.

T. : time of treatment; T. +12 hrs : 12 hours post-treatment; MR : multiplication rate; SI : synchronicity index; RI : resistance index.

\section{DISCUSSION}

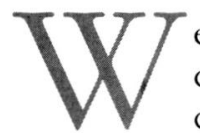

e have previously observed that the degree of sensitivity to chloroquine of different species, subspecies and even strains of the murine malaria parasites differed from one parasite to the other, and that there was a relationship between their sensitivity and their specific biology (Beauté-Lafitte et al., in press). We have interpreted asynchronous infections as resulting from an extended latency of merozoites, a stage apparently insensitive to the drug (Cambie et al., 1991).

The data presented in this work show that the particularly strong resistance of $P . y$. nigeriensis to chloroquine is not related to an innate resistance of the mid-term trophozoite, which is the sensitive stage to chloroquine of P. v. petteri (Cambie et al., 1991), of $P$. falciparum (Landau et al., 1992) and very likely of all the malaria parasites. The MTs of $P . y$.nigeriensis are shown to be normally sensitive to chloroquine. By chosing the proper timing for the inoculation of Rs and YTs, separated from the other stages by the Percoll-glucose gradient, various degrees of synchronization can be obtained. Using this controlled synchronization, we demonstrate that a relationship between the degree of synchronicity of the infection and its sensitivity to chloroquine exists.
It appears that simple biological factors like the selection of strains with latent merozoites and the consequent asynchronism may be responsible for drug resistance to chloroquine. This new hypothesis suggests new strategies for drug design and targeting. It becomes gradually obvious that merozoites, either per se or by the impairment of their penetration into RBCs, are a most suitable target for chemotherapy.

The rodent malarias so widely used for drug testing provide a large variety of models for chemotherapy studies. Work on chronobiology and chronotherapy can yield important information when a judicious choice is made in selecting the strain best adapted to screening or interpreting results on the mode of action of drugs.

\section{ACKNOWLEDGMENTS}

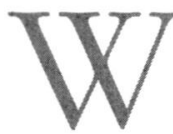

e are very much indebted to R.S. Bray for revising this paper and to $\mathrm{H}$. Ginsburg for his many helpful remarks and constant help.

This work was supported by grant from the Research and Development Program of the E.E.C n ${ }^{\circ}$ TS3-CT930228. 


\section{REFERENCES}

Beauté-Lafitte A., Altemayer-Caillard V., Gonnet-Gonzales F., Ramiaramanana L., Chabaud A.G. and landau I. The chemosensitivity of the rodent malaria. Relationships with the biology of merozoites. International Journal for Parasitology, in press.

Beauté-Lafitte A., Chabaud A.G., Altemayer-Caillard V., Deharo E., Gautret PH. and Landau I. Schizogonie de Plasmodium yoelii nigeriensis. Rôle des mérozoïtes latents. Annales de Parasitologie Humaine et Comparée, 1993, 68, n 5/6, 211-219.

Caillard V., Beauté-Lafitte A., Chabaud A.G. and landau I. Plasmodium vinckei petteri : Identification of the stages sensitive to arteether. Experimental Parasitology, 1992, $75,449-456$.

Cambie G., Caillard V., Beauté-Lafitte A., Ginsburg H., Chabaud A.G. and Landau I. Chronotherapy of malaria : Identification of drug sensitive stage of parasite and timing of drug delivery for improved therapy. Annales de Parasitologie Humaine et Comparée, 1991, 66, 14-21.

Cambie G., Landau I. and Chabaud A.G. Niches horaires des trois espèces de Plasmodies coexistant chez un Rongeur de Centrafrique. Comptes Rendus de l'Académie des Sciences de Paris, 1990, 310, 183-188.

Deharo E., Gautret PH., Ginsburg H., Chabaud A.G. and LANDAU I. Synchronisation of Plasmodium yoelii nigeriensis and Plasmodium yoelii killicki infection in the mouse by means of percoll-glucose gradient stage fractionation. Determination of the duration of the schizogonic cycle. Parasitology research. 1994, 80, 159-164.

Diggens S.M. and Gregory K. Comparative response of various rodent malarias to chemotherapy. Transactions of the Royal Society of Tropical Medicine and Hygiene, 1969, 63, 7 .

Landau I. and Chabaud A.G. Nouvelles données sur le cycle nycthéméral des Plasmodium. Comptes Rendus des séances de l'Académie des Sciences de Paris, 1980, 291, série D, 985-988.

Landau I., Lepers J.P., Ringwald P., Rabarison P., Ginsburg H. and Chabaud A.G. Chronotherapy of malaria : Improved efficacy of timed chloroquine treatments of patients with Plasmodium falciparum infections. Transactions of the Royal Society of Tropical Medicine and Hygiene, 1992, 86, 374-375.

Pande A. and Dutta G.P. Chemotherapeutic response of Plasmodium yoelii nigeriensis to antimalarial drugs. Indian Journal of Malariology, 1982, 19, 121-124.

WARHURST D.C. and KILLICK-Kendrick R. Spontaneous resistance to chloroquine in a strain of rodent malaria (Plasmodium berghei yoelii). Nature, 1967, 213, 10481049.

White N.J., Watt G., Bergqvist Y. and Njelesani E.K. Parenteral chloroquine for treating falciparum malaria. Journal of infectious diseases, 1987, 155, 192-201.

Accepté le 2 mai 1994 